\title{
Learning and Developing Individual Exercise Skills (L.A.D.I.E.S.) for a Better Life: a physical activity intervention for black women
}

\author{
Melicia C. Whitt-Glover, Ph.Da, Moses V. Goldmon, Ed.D ${ }^{\mathrm{b}}$, Njeri Karanja, Ph.D ${ }^{\mathrm{c}}$, Daniel P. \\ Heil, Ph.D ${ }^{d}$, and Ziya Gizlice, Ph.D \\ Melicia C. Whitt-Glover: mwhittglover@gramercyresearch.com; Moses V. Goldmon: mgoldmon@shawu.edu; Njeri \\ Karanja: njeri.karanja@kpchr.org; Daniel P. Heil: dheil@montana.edu; Ziya Gizlice: ziya_gizlice@unc.edu \\ aGramercy Research Group, 500 W. $4^{\text {th }}$ Street, Suite 203, Winston-Salem, NC27101, USA, \\ Phone: (336) 293-8540, EXT 110, Fax: (336) 608-4465 \\ bInstitute for Health, Social and Community Research \&Shaw University Divinity School, 118 East \\ South Street, PO Box 2090, Raleigh, NC27601, USA, Phone: 919-546-8256 \\ 'Kaiser Permanente Center for Health Research, 3800 N. Interstate Avenue, Portland, OR97227, \\ USA, Phone: (503) 335-2400 \\ dMontana State University, Dept. of Health and Human Development Movement Science, Human \\ Performance Lab, H\&PE Complex, Bozeman, MT 59717-3540, USA, Phone: (406) 994-6324 \\ eCenter for Health Promotion and Disease Prevention, University of North Carolina at Chapel Hill, \\ Chapel Hill, NC 27599-7426, USA, Phone:919-571-1251
}

\section{Abstract}

Physical activity (PA) is low among African American women despite awareness of its positive impact on health. Learning and Developing Individual Exercise Skills for a Better Life (L.A.D.I.E.S.) compares three strategies for increasing PA among African American women using a cluster randomized, controlled trial. Underactive adult women from 30 churches $(n=15$ participants/church) were recruited. Churches were randomized to a faith-based intervention, a non-faith based intervention, or an information only control group. Intervention groups will meet 25 times in group sessions with other women from their church over a 10-month period. Control group participants will receive standard educational material promoting PA. All participants will be followed for an additional 12 months to assess PA maintenance. Data will be collected at baseline, 10, and 22 months. The primary outcome is PA (steps/day, daily moderate-to-vigorous PA). We expect treatment effects indicating that assignment to either of the active interventions is associated with greater magnitude of change in PA compared to the control group. In exploratory analyses, we will test whether changes in the faith-based intervention group are greater than changes in the non-faith-based intervention group. L.A.D.I.E.S. focuses on a significant issueincreasing PA levels-in a segment of the population most in need of successful strategies for improving health. If successful, L.A.D.I.E.S. will advance the field by providing an approach that is successful for initiating and sustaining change in physical activity, which has been shown to be a primary risk factor for a variety of health outcomes, using churches as the point of delivery.

(C) 2012 Elsevier Inc. All rights reserved

Correspondence to: Melicia C. Whitt-Glover, mwhittglover@gramercyresearch. com.

Database linking and Accession numbers: NCT ID: NCT00991731

Publisher's Disclaimer: This is a PDF file of an unedited manuscript that has been accepted for publication. As a service to our customers we are providing this early version of the manuscript. The manuscript will undergo copyediting, typesetting, and review of the resulting proof before it is published in its final citable form. Please note that during the production process errors may be discovered which could affect the content, and all legal disclaimers that apply to the journal pertain. 


\section{Keywords}

Physical activity; African American women; spirituality; health; faith

\section{Introduction}

The benefits of increased physical activity on diseases and risk factors such as cardiovascular disease, hypertension, diabetes, obesity, and some forms of cancer, particularly among minorities and women, are well documented [1-4]. Despite these benefits, physical activity levels among minorities and women, particularly African American women, remain low. Low levels of physical activity in this group begin in childhood and adolescence [5] and continue into adulthood [6,7]. National surveillance data indicate that only $24 \%$ to $36 \%$ of African American adults participate in regular physical activity (at least 30 minutes of moderate-intensity physical activity on at least 5 days per week or at least 20 minutes of vigorous-intensity physical activity on at least 3 days per week) [8]. These data also indicate that African American women have lower levels of physical activity participation than their male counterparts, regardless of age, education, income level, marital status, employment status, or region in which respondents reside [911]. The low level of physical activity among African American women is disturbing given that they have disproportionately high risk for multiple chronic diseases and their corresponding complications [12].

Successful and sustainable strategies are needed to increase physical activity participation levels in African American women; yet, few studies have specifically targeted this population, perhaps because African Americans have been considered a hard-to-reach population. The emergence of faith-based and church-placed research studies and health programs has changed the notion that African Americans are hard to reach. Several churchbased interventions to promote health among African Americans, particularly African American women, have been shown to be successful for weight loss [13-15], smoking cessation [16] and reduction of risk factors for cardiovascular disease [17-21]. A recent review highlighted the success of several faith-based physical activity interventions and suggested this approach is promising [22]. However, many faith-based interventions have only used the church as a venue of intervention, without incorporating the spiritual tenets of the church into the interventions themselves. A strong association between spirituality/ religion and health is well documented in the literature in a number of groups including African Americans [23-27]. Additional work is needed to determine whether strategies that incorporate the spiritual beliefs of congregants who participate in lifestyle interventions including physical activity have additional benefits compared to standard or usual care conditions, or to programs that use places of worship only as a venue to deliver interventions.

The purpose of this report is to describe the development and methodology of an intervention named Learning and Developing Individual Exercise Skills (L.A.D.I.E.S.) for a Better Life, a cluster randomized controlled trial designed to test whether incorporating spiritual tenets of the faith of study participants increases and maintains physical activity among underactive African American women compared to a self-guided control group.

\section{Background and Rationale}

Churches are recognized as an ideal setting for health education and health promotion efforts, particularly among African Americans, because of their central role in spiritual guidance, communication, social support, and networking [28-30]. Among low-income and minority communities where the benefits of community programs to implement health 
promotion and disease prevention activities have been documented, churches are often the community's first source of support $[31,32]$. The Barna Group reports that $47 \%$ of all American adults, $52 \%$ of African Americans, $50 \%$ of women, and $51 \%$ of Southerners report attended a religious service in the past week [33]. Data from the Pew Forum on Religion and Public Life indicated that, compared to the U.S. population, a higher proportion of African Americans report having absolutely certain belief in God, say religion is very important in their lives, pray at least daily, interpret Scripture literally, and attend worship services at least weekly [34]. Within historically black churches, $81 \%$ of the adult population identified with a religious group, $77 \%$ of whom reported being Christian [35]. Church membership and associated activities are particularly important to African American women, who are more likely to report attending church, reading the Bible, attending Sunday school classes, or participating in small groups that meet during the week than any other race/ethnic and gender group [33].

At the same time, many African American churches consider health as part of their mission and many of their activities reflect an emphasis on wellness of mind, body, and spirit. A significant number of churches have "health ministries" that offer a variety of resources that can be beneficial to health promotion efforts [32]. Several studies have examined the association between spirituality/religion and health-related behaviors among African Americans. The combined data suggest a strong association between spirituality/religion and health. An exploratory study of cancer screening behaviors among African Americans showed an association between religion and spirituality and communication with health care providers, personal health assessment, and dietary behaviors [23]. Focus group interviews conducted with African American women who reported being active participants in health ministry programs within a faith community reported that prayer, pastoral support, and trust in the congregational nurse were among factors that influenced their engagement in healthy lifestyles [24]. Cross-sectional data among 260 African American, Caribbean, and HispanicBlack women examined associations between spirituality, diet, and exercise, and showed a positive association between spiritual growth and physical activity and diet [25]. African American women who participated in a weight loss intervention in a church setting reported less disordered eating attitudes and less personal distrust at baseline and higher weight loss at follow-up than African American and white women who participated in the same intervention in a university setting [26]. Focus group data found that African American women were more likely than African American men to recognize the relationship between spirituality and health, suggesting that African American women may be more amenable to a church-based health promotion program [27]. African American women also recognized the necessity of good physical health for being a good Christian, believed that being physically active and eating healthy contributed to being a better Christian, and described some poor health-related behaviors (e.g., overeating) as sin. Combined, data on church attendance, religious beliefs, and identified linkages between spirituality and health, suggest that it is reasonable to expect that a faith-based intervention could be a successful strategy for changing health behaviors among African Americans, particularly women.

The rationale for implementing health promotion interventions among African Americans in church settings has generally been related to the role of churches in African American communities. An important part of how the role of churches influences health is related to the faith tenets and biblical principles that are taught in churches. It is important to note the distinction between faith-based and faith-placed interventions. Faith-based interventions incorporate tenets of the faith-based organization (e.g., religious beliefs, scriptural references) and involve the faith-based organization in the planning of the intervention from beginning to end [36]. Faith-placed interventions are developed outside the faith-based organization and simply carried out within the church, but do not attempt to incorporate elements of the faith-based organization [36]. Collaborative programs implemented in 
churches have the most potential for success, and programs that are not collaborative may limit program acceptability, sustainability, fidelity and, ultimately, program success. In addition to distinguishing between faith-based and faith-placed research activities, Lasater et al identified four levels by which health-related programs are carried out in churches [29]. Level I programs use churches only as venues for participant recruitment. Level II programs are delivered on-site at churches but generally do not include partnerships with churches for program development. Level III programs include congregation members in program delivery, and Level IV programs integrate spiritual elements, scriptures, and messages within program content. Lasater and colleagues argue that more research is needed on Level III and IV programs in order to better maximize the strengths of both faith organizations and academic partners.

Researchers have also identified elements necessary for community-based programs to be considered culturally and spiritually sensitive. Cultural sensitivity can be conceptualized by two primary dimensions-surface structure and deep structure [37]. Surface structure is described as matching intervention materials and messages to observable characteristics of the population of interest, such as commonly used products, behavior patterns, and environmental and social contexts in which behaviors occur. Deep structure refers to programs that reflect ways by which culture, social, psychological, environmental, and historical factors and values can influence behavior, and particularly how these factors influence behaviors across different population subgroups. In the case of programs implemented in churches, attention to deep structure involves understanding and recognition of how religion and faith influence behavior in the population of interest. Attention to surface and deep structure have also been proposed by other researchers as necessary for successfully implementing culturally appropriate behavior modification interventions among population subgroups, particularly African Americans [36, 38]. Two reviews have highlighted additional essential elements for successful health promotion programs in churches $[36,39]$. These elements include a focus on positive health values, communityfocused interventions, focus on changing health behaviors, emphasis on supportive relationships through existing social systems, interventions that incorporate the sociocultural environment and can be delivered by the community, and ongoing plans for program sustainability.

To our knowledge, only one published study has attempted to compare the impact of a faithbased vs. a non-faith-based curriculum on physical activity levels among African Americans. Project Joy compared a standard or spiritual behavioral intervention with a selfhelp control group to impact nutrition and physical activity among 529 African American women $\geq 40$ years in 16 churches [40]. The standard intervention included weekly sessions in churches and focused on nutrition and physical activity for 40 weeks. The spiritual intervention included the same curriculum, with the addition of group prayer and scriptures read at the beginning and end of each session. Project-related messages and announcements were included in church bulletins, but this did not add to the spirituality of the intervention. The self-help intervention included standardized materials from the American Heart Association on healthy eating and physical activity. Results from the study showed a near significant change in self-reported energy expenditure within both active intervention groups (standard intervention and spiritual intervention) after one year but no between group differences. As noted by the investigators, a major limitation of program implementation was that the standard intervention group introduced spirituality into their sessions from the beginning without staff assistance (e.g., incorporated scripture and prayer into intervention sessions) because these practices are a regular part of the church culture, and there was no discernable difference between the two intervention conditions. These findings highlight the potential difficulty of implementing purely secular interventions in faith settings. Project Joy added prayers and scriptures to a standard curriculum but found that these additions were 
not sufficient to make the curriculum truly faith-based and separate from the secular condition, particularly since participants in the secular condition added prayers and scriptures on their own. Additional research is needed that develops and test a truly faithbased curriculum against control conditions. To truly test the faith-based strategies, curricula need to carefully and fully incorporate faith tenets and theological concepts throughout the curriculum, and the curriculum should be taught from a biblical standpoint. Once true faithbased curricula have been established and tested, additional research is needed to determine whether a faith-based curriculum is more effective than a similar, non-faith-based curriculum to improve chronic disease risk factors (e.g., physical activity, nutrition) among African Americans in churches.

L.A.D.I.E.S. for a Better Life is designed to address the elements that have been shown to be necessary to successfully implement a behavior change intervention in a faith-based setting. L.A.D.I.E.S. will test whether incorporating spiritual tenets of the faith of study participants increases and maintains physical activity above and beyond a standard self-guided condition among underactive African American women. In a secondary analysis, L.A.D.I.E.S. will compare the faith-based intervention to the non-faith-based intervention to determine whether adding spiritual components to the intervention has any additional impact on physical activity levels. The secondary analyses will provide estimated effect sizes that can be used in a larger study that would be powered to compare a faith-based curriculum with comparable non-faith-based curricula. The first step, however, is to develop, implement, and evaluate a true faith-based curriculum, which is the basis of L.A.D.I.E.S.

\section{Methods}

\section{Theoretical Framework}

L.A.D.I.E.S. is guided by a conceptual model that integrates key concepts from social ecological theory, which posits that interventions need to build upon or target "leverage points" for adult behavior [41], and social cognitive theory, which fundamentally argues that cognitions resulting from individuals' interactions with the physical and social environment contribute to behavior patterns $[42,43]$. Leverage points are features of the environment, particularly the social environment, that exert a disproportionate influence on an individual's behavior and, ultimately, health. In the African American community the church, as the institutional embodiment of religion and faith, is a key leverage point. Interventions focused on African Americans that are carried out in churches and make use of the "natural" role of the church have substantial potential for promoting regular physical activity in the African American community, and interventions that specifically incorporate core religious principles (i.e., faith-based) may have even greater potential for influencing health.

Social cognitive theory further refines the intervention by highlighting specific mechanisms by which the L.A.D.I.E.S. intervention will likely contribute to positive changes in physical activity. Social cognitive theory fundamentally argues that cognitions resulting from individuals' interactions with the physical and social environment contribute to behavior patterns, such as regular physical activity $[42,43]$. Particularly powerful is self-efficacy or the extent to which individuals believe they can successfully perform the advocated behavior, even when confronted with barriers to performance. Also important, however, are the incentives or the inherent values placed on and external reinforcements for the advocated behavior, and the level of social support individuals receive from their environment for the advocated behavior. L.A.D.I.E.S. contributes to increased physical activity among African Americans through promoting multiple dimensions of physical activity-related self-efficacy, including both general self-efficacy and self-regulatory self-efficacy; increasing physical activity by creating added incentives for the behavior; and increasing physical activity by 
strengthening a pivotal social network and increasing social support for regular physical activity.

\section{Overview of Study Design and Aims}

L.A.D.I.E.S. is designed to identify ways to increase physical activity among underactive African American women. The study utilizes a three group, cluster-randomized design, with 10 clusters of churches assigned to one of three conditions. Cluster 1 received a faith-based intervention curriculum that combined behavior change and social learning theories with spiritual tenets of the involved churches to increase physical activity. Cluster 2 received a traditional non-faith-based intervention curriculum based on principles of behavior change and social learning theories to increase physical activity, while cluster 3 received standard written materials to increase physical activity. The three-group design allows us to test the primary hypothesis that the faith-based and non-faith-based intervention curricula are more effective than standard written advice for increasing physical activity. We are also interested in examining, as a secondary hypothesis, differences between the two active intervention conditions, and hypothesize that the faith-based curriculum will be more acceptable and more effective than the non-faith-based curriculum among study participants.

\section{Intervention Content}

The L.A.D.I.E.S. curriculum was initially informed by a luncheon with $\sim 60$ representatives from churches in the target community (e.g., clergy, health ministry leaders, first ladies, other church staff) to discuss strategies by which an academic institution and the faith community could partner to address health issues. From the meeting, church representatives identified health care access, health information, and health promotion programs as three primary areas of interest for partnerships. One of the authors (MCW) conducted key informant interviews with nine local pastors to understand their knowledge, attitudes, and beliefs around health promotion in churches, and to collect their thoughts on strategies for increasing physical activity, specifically through health promotion programming, in faith settings (data not published). Subsequently, a pilot study conducted by one of the authors (MCW) as a part of a National Institutes of Health training grant (K01 HL70449), evaluated the impact of a six-month church-based intervention on physical activity levels among underactive African Americans in four churches and provided information on expected effect sizes in preparation for a larger trial to evaluate a physical activity intervention in African American churches (L.A.D.I.E.S.). Results from the pilot study are published elsewhere [44].

The curriculum for the L.A.D.I.E.S. intervention contains elements of the pilot study and other successful curricula for increasing daily physical activity in adults [44-46], and was designed to be in line with the number of sessions offered in similar behavior change interventions focused on physical activity. The curriculum length was also in direct response to feedback from participants in the pilot church-based physical activity intervention who suggested that additional sessions would have been more desirable. Session content, written by the study Principal Investigator (MCW) and Co-Investigator (MVG), focused on applying the three key mechanisms in the conceptual model expected to influence behavior - self-efficacy, incentives, and social support. The intervention content focused heavily on self-efficacy because research has consistently demonstrated that self-efficacy significantly predicts the adoption and maintenance of physical activity across a wide range of study designs and diverse samples [47]. Moreover, self-efficacy is the central component of social cognitive theory [48] and, as such, was central to our conceptual framework.

To address issues that were noted in previous studies attempting to compare faith-based vs. non-faith-based curricula, we carefully and deliberately modified several elements in an 
attempt to keep the faith-based and non-faith-based conditions distinct. First, all study sessions were held in the family life center of a centrally located church. Thus, the study was church-placed, but not held in a sanctuary, which we expected would help women to understand that L.A.D.I.E.S. is not automatically a faith-based program. During recruitment and pre-screening sessions, study staff thoroughly explained the three types of interventions and the importance of adherence to the assigned intervention condition. Churches that were assigned to the non-faith-based or control condition were told they would have the opportunity to receive the faith-based curriculum at the end of the official study period. To our knowledge, these strategies were helpful in convincing women to adhere to their assigned study conditions.

Second, to ensure cultural appropriateness, we decided to provide a standard script for opening each session that would appeal to faith-based and non-faith-based intervention participants. Intervention sessions in both active arms of the intervention began with an opening secular quote OR prayer. To maintain consistency across groups, the opening quote and prayer were pre-written and included in the participant materials and the group leader manual. In the faith-based groups, the group leader read the prayer aloud or, if the group desired, the group read the prayer in unison. In the non-faith-based groups, the group leader read the secular quote of the day aloud. In this way, we attempted to create the feel of starting an activity by "centering" in the non-faith-based groups, which is often the purpose of prayer prior to an activity beginning. Further, prayers and quotes were specifically related to the theme/content of the session. For example, in the session on social support, an African proverb was used as the opening quote for the non-faith-based group, "If you want to go fast, go alone. If you want to go far, go together". Participants paused for a moment of silent reflection on the quote. In the session on social support for the faith-based group, the prayer focused on being thankful for the program and asked for strength and guidance to assist participants with seeking help in their lives. Further, the prayer expressed thanks to God for a mindset, the desire, and the knowledge to make physical activity a daily part of life. By deliberately incorporating a session-appropriate prayer or opening quote, we were able to control the amount of spirituality that was incorporated into the non-faith-based curriculum, which has been a limitation in previous studies comparing faith- and non-faith-based curricula [40]. Of course, we did not prohibit non-faith-based groups from praying, if they so desired. In those cases, the group leader allowed a participant to lead the prayer and the group leader recorded the general themes/content of the prayer for later comparison with the faith-based prayer theme for that particular session.

Third, during the skill training segment of each session, participants received general information on the topics to support physical activity, as outlined in Table 1. Each topic was supplemented by reading material not directly related to physical activity, but that supported either the faith-based or non-faith-based intervention strategies. For example, the outside reading that was used to support the social support session for the non-faith-based group was a reading and exploration of the lyrics to the song "Lean on $M e$ ". In contrast, participants in the faith-based group read and discussed two biblical passages that highlighted instances of individuals who relied on assistance from others to complete a task (Judges 4: 8-9 and Nehemiah 6: $1-3$ ).

\section{Control Group Content}

The control group received a booklet, "Exercise \& Physical Activity: Your Everyday Guide from the National Institute on Aging" [49] and instructions on how to use self-guided materials. A wide variety of control conditions were considered given the reluctance of churches to be randomized to a low or no attention control condition [40,50], including an alternative intervention not focused on physical activity. We ultimately decided to provide only standardized printed materials rather than an attention control group because this 
approach mimics a standard public health/health education approach and allowed us to clearly delineate the impact of the faith-based and non-faith-based curricula compared to standard practices. However, to encourage control churches and participants to remain in the study, we offered participants in the control groups one of the active interventions (based on church preference) at the end of the study.

\section{Maintenance}

Following the 10-month intervention period, all participants (intervention and control) were followed for an additional 12 months to measure the long-term impact of either intervention condition compared to the control group. During the 12-month maintenance period, participants received approximately six postcard mailings from study staff (one every other month). Postcards were holiday greetings, birthday greetings, and general information encouraging continued physical activity. Mailed postcards allowed us to quickly follow up with individuals for whom postcards were returned as undeliverable, to increase our chances of being able to contact individuals for follow-up after 12 months. If postcards were returned as undeliverable, study staff attempted to contact the study participant or church representative to get updated contact information. Participants received no other formal communication from study staff during the maintenance period. Final data collection occurred 22 months after baseline (after 10 months of intervention and 12 months of maintenance).

\section{Intervention Implementation and Monitoring}

\section{Intervention Implementation}

L.A.D.I.E.S. sessions were scheduled to last for 90 minutes each. This included a 30-minute physical activity session (led by a trained exercise leader) and 60 minutes of group discussion (led by a trained Community Health Worker). Group discussion content was standardized to ensure consistent delivery across the two active arms. The group discussion format was similar for each session and included six segments: 1) opening thought OR prayer ( $\sim 5$ minutes); 2 ) review of participant progress in implementing the strategies recommended for changing their physical activity from the previous session, including group-based problem solving strategies informed by the five-step approach from the continuous care problem-solving model [51] ( 10 minutes); 3) skill training to discuss new topics, which were illustrated through biblical passages (faith-based curriculum) or secular readings (non-faith-based curriculum) ( $\sim 30$ minutes); 4) exercise session ( $\sim 30$ minutes); 5) goal-setting ( $\sim 10$ minutes); and 6$)$ final review, wrap up, and check out ( $\sim 5$ minutes). At the end of each session, participant materials included $2-3$ take home points (e.g., "If you don't remember anything else from the session, remember this...") to highlight the most important points to remember from the session.

Sessions $1-16$ occurred weekly, sessions 17 - 20 occurred bi-weekly, and sessions $21-24$ occurred monthly (10 total months of contact). This gradual reduction in meeting frequency aided in the transition from regular group sessions to independence by the end of the study, while still maintaining expected changes in physical activity. We held trouble shooting sessions after every four scripted sessions to allow participants to discuss and problem solve about specific issues they might have been facing and to ask technical questions about content covered during previous sessions. Two content experts (MWC and MVG) led the trouble shooting sessions.

L.A.D.I.E.S. sessions were taught by Community Health Workers (CHWs), who were recruited from the local community and hired as part-time, hourly paid study staff. CHWs for the faith-based curriculum were familiar with general biblical principles and had some experience and comfort with reading, interpreting, and teaching biblical passages, were 
familiar with the culture within African American churches, and had experience in leading group discussions. Intervention leaders for the non-faith-based curriculum had knowledge and educational background in health promotion or health behavior change, were familiar with the culture within African American churches, and were comfortable leading group discussions. For gender matching, all CHWs were women. CHWs were not required to be exercisers to lead intervention groups; however, they were strongly encouraged to work toward the same behavioral goals as the study participants since their personal experiences would be useful in group discussion and problem solving. None of the CHWs led sessions for churches at which they were members.

The primary goal for L.A.D.I.E.S. was to increase daily physical activity, primarily through gradual increases in daily walking. Walking was chosen as the primary form of activity because it is one of the most commonly reported activities among African American women $([9,10])$. The targeted behavioral goal was to, at minimum, increase daily walking to $\geq$ 2,000 steps per day above baseline levels during the active intervention. This behavioral goal was based on the current recommendation for daily walking advocating adults to walk at least 8,000 to 10,000 steps each day [52-55], and that one way to achieve this goal is to add at least 2,000 steps to the normal daily routine [56]. Participants were encouraged to increase daily step counts by at least 2,000 steps per day until they reach 10,000 steps per day, after which participants were encouraged to maintain physical activity behaviors or to continue increasing. We also encouraged participants to increase daily moderate-to-vigorous physical activity to $\geq 150$ minutes per week, and to increase moderate-to-vigorous physical activity bouts to $\geq 10$ minutes each, which has been recommended in the 2008 Physical Activity Guidelines for Americans [57]. Participants were encouraged to achieve this goal by aiming for 30 minutes of physical activity on at least five days per week but, preferably, daily which is in line with the 1995 physical activity recommendation from the Centers for Disease Control and Prevention and the American College of Sports Medicine [58]. We encouraged participants to maintain changes in physical activity levels during the 12 month follow-up period.

To facilitate gradual increases in physical activity, the exercise component of the group intervention sessions included warm-up, an activity period, and cool down. Participants began with a 15-minute exercise session. One minute was added at each weekly exercise session until the participants reached 30 minutes ( session 16). All exercise sessions during the remaining group meetings lasted for 30 minutes. Participants were encouraged to engage in the same amount of activity that was performed during the group exercise session for at least five days during the ensuing week. Inclusion of an exercise period during the weekly sessions allowed an opportunity for participants to learn methods for proper warm-up and cool-down prior to and following physical activity, as well as time to rehearse using physical activity incentives (e.g., exercise videos, hand weights), and to understand the body's physiological reactions to moderate-intensity physical activity (i.e., many participants in the pilot study were not exactly sure what moderate-intensity physical activity felt like (e.g., how hard should they be breathing, what should heart rate be?) and may not have engaged in the appropriate intensity-level for physical activity outside of class without opportunities to rehearse activity in class). Gradually increasing physical activity allowed participants to more easily determine ways to adapt their lifestyles to allow them to incorporate physical activity daily.

\section{Intervention Monitoring}

In an attempt to ensure that we would have two distinct intervention programs for comparison with the control condition at the end of the study, we incorporated several strategies to maintain and assess intervention adherence and fidelity. One strategy for enhancing program fidelity was to develop appropriate study manuals and training materials 
to standardize training across CHWs [59]. Training of CHWs consisted of didactic and experiential learning. Material was presented in lecture format, conducted primarily as if CHWs were study participants. During training, CHWs participated in group sessions as they were conducted in the study, and were required to perform the self-regulatory skills (e.g., goal setting, self-monitoring) and physical activity that were required of the participants in the study. Thus, not only were CHWs trained in the background knowledge (e.g., exercise science basics, study protocol, session content), but they also experienced what it was like to be a group member and a participant in the study. The study Principal Investigator (MCW) led $2-3$ exemplar sessions with CHWs. Following, CHWs received a group leader's guide that contained scripted content for each intervention session, including special notes and areas of emphasis within each session, and a copy of the participant materials for the session. Each CHW observed at least two ongoing intervention sessions (typically one faith-based and one non-faith-based session). CHWs led at least one practice session, with other CHWs and study staff acting as group participants and providing feedback. Each CHW practiced two "live" sessions with ongoing intervention groups. Study staff provided feedback and additional training for CHWs as needed. All training activities were completed prior to a CHW being assigned a group to lead. Once a CHW was assigned to lead her own group, an experienced $\mathrm{CHW}$ attended and observed the first five intervention sessions conducted by the new $\mathrm{CHW}$. The experienced $\mathrm{CHW}$ provided feedback and suggestions for additional training for the new $\mathrm{CHW}$ as necessary.

Throughout the study, we were particularly interested in assessing any potential contamination of treatment and control groups. During each session, CHWs maintained careful process notes regarding session discussion, questions asked and, in particular, biblical references made that were not specifically included in the scripted session notes. For example, if a participant in the non-faith-based group used a biblical scripture to highlight a point during the group problem solving session, the $\mathrm{CHW}$ recorded the scripture and the content of the discussion. Monthly, we assessed health-related activities at the church level, including activities conducted in conjunction with another church. At the 10- and 22-month data collection visits, participants will answer questions about whether they know anyone else who is participating in L.A.D.I.E.S. and, if so, we will note their relationship to the individual.

\section{Church and Participant Recruitment}

L.A.D.I.E.S. includes 30 churches, 10 churches per randomization arm. Each church was required to recruit $12-15$ participants who met eligibility criteria. Recruitment of churches for participation in this study was facilitated by personal contacts with pastors and health ministry leaders from churches that were involved with our previous programs, attendance at a local ministerial alliance, and word of mouth. In addition, we recruited members of the community who were familiar with and actively engaged in the faith community as consulting study recruiters. Inclusion criteria for churches included 1) documented support of the pastor for implementing a program in the church as demonstrated by a signed covenant agreement; 2) willingness to accept randomization to either of the three intervention conditions; and 3) demonstrated ability to recruit 15 study participants who met study eligibility criteria.

When a church expressed initial interest in participating in the study, a meeting was set between the study recruiter and an official at the church (usually the church pastor). The study recruiters showed a 5-minute video featuring footage of the study investigators and a L.A.D.I.E.S. class. The video also described the randomization process. The church official also received a study brochure outlining study procedures in written format. If the church official indicated continued interest in participating in the study, s/he was asked to designate 
a site captain from the church to serve as the primary liaison between the church members and study staff. Prior to engaging in study-related activities, the site captain was briefed by study staff on study-related procedures, study inclusion criteria, and her responsibilities with regard to recruiting and retaining study participants and participating in study-related activities (including attending and participating in intervention sessions and assisting with scheduling and tracking participants to participate in baseline and follow-up data collection visits). Site captains received a modest monthly stipend ( $\$ 100 / \mathrm{month})$ for their participation in the study.

Within each church, study participants were recruited using announcements during Sunday morning worship services and weekly activities, flyers placed throughout the church, inserts in the Sunday bulletin and other church communications (e.g., church newsletters). Interested individuals participated in an information session, led by a recruiter, during which an informational video was shown and the program was described. Potential study participants completed a pre-screening form to determine study eligibility. Eligible participants included African American women $\geq 18$ years of age who reported that they were participating in $<150$ minutes per week of moderate/vigorous physical activity. Participants had no physical limitations or disabilities that would limit physical activity participation, and no contraindications for increasing daily physical activity, such as recent myocardial infarction or congestive heart failure. All participants had to be willing to participate in a two-year study.

Current physical activity level was assessed using a modified version of the International Physical Activity Questionnaire (IPAQ) to determine study eligibility [60]. The modified IPAQ provided self-reported estimates of weekly participation (in minutes) in vigorous- and moderate-intensity PA and brisk walking, and has been shown to have high test-rest reliability (0.89) and modest correlations ( 0.30$)$ with objective measures of PA in the target population [61]. Participants were further evaluated using the Physical Activity Readiness Questionnaire (PAR-Q), which has been shown to be a valid screening tool for preparticipation in physical activity [62-65]. The PAR-Q included seven questions that assess the presence or absence of several known risk factors that preclude participation in moderate-to-vigorous physical activity without consent from a medical professional. Participants who answered "yes" to any question on the PAR-Q were required to obtain medical clearance from their primary care physician prior to participating in this program. Obtaining medical clearance did not appear to be a barrier to participation in this study population. All potential participants were informed of the study design and interventions, the risks and benefits of participation, their rights and responsibilities as research participants, and alternatives to participation. Participants were required to sign an informed consent document prior to screening. In keeping with the Health Insurance Portability and Accountability Act (HIPAA), we obtained consent from all participants to collect and share personal health information for research purposes prior to enrollment in the study.

\section{Randomization of Churches}

The study used a group randomized three parallel group study design. Participating churches were randomized to the faith-based intervention, the non-faith-based intervention, or a control group. A single randomization table was created using SAS 9.2 (SAS Institute, Cary NC) with a randomization allocation ratio of 1:1:1. A blocked randomization with a block size of three was used to ensure balance across study groups. All churches were required to agree to randomization and to accept the randomization assignment prior to participation in the study. Opaque envelopes were sequentially numbered and labels containing randomization information placed into the envelopes. After the initial baseline data collection visit (part 1 of 2) at each church, the opaque envelope was opened to determine 
the study assignment for each church. Churches were informed of their random assignment at the second data collection visit (approximately 2 weeks after initial baseline data collection).

\section{Outcome Variables}

Outcome variables were collected at baseline, and will be collected at 10 months (immediately after the end of group sessions), and 22 months (one year after the end of group sessions) for all participants. All data are collected by trained research staff at the church from which the participant was recruited in order to minimize participant burden. Participants receive $\$ 75$ for completing all three rounds of data collection (\$10 after the baseline visit, $\$ 15$ after the 10 month visit, and $\$ 50$ after the 22 month visit). Participants who miss a scheduled data collection visit are contacted for up to four weeks after the missed visit to attempt to collect the data.

\section{Physical Activity}

Daily walking, which was the primary outcome measure and the measure on which the study was powered, is assessed using a pedometer and a physical activity log in which to record the daily number of steps taken by each study participant. All intervention participants received the New Lifestyle Pedometer 2000 (NL-2000) at the beginning of the study, and were asked to keep a record of daily walking on a study log sheet throughout the active intervention period. Control participants did not receive pedometers. Participant logs were reviewed, and feedback was provided, at the beginning of each group session during the review of participant progress. The New Lifestyles Lifecorder 2160 (NL-2160) is used for data collection at baseline, 10 months, and 22 months. The NL-2160 works via the same mechanism as the NL-2000, but stores walking data for up to 60 days. NL-2160 pedometers are sealed for data collection to prevent participants from altering their normal physical activity patterns. Walking data are measured for 14 consecutive days (two weeks) at each data collection visit. Daily step counts recorded on the pedometer will be used for analyses.

Participation in daily bouts of moderate-to-vigorous physical activity is assessed as a secondary measure of physical activity using the Actical ${ }^{\circledR}$ accelerometer (Phillips Respironics, Inc; Bend, OR). Participants wear wrist-mounted accelerometers for 14 consecutive days at the baseline, 10 month, and 22 month data collection visits. To optimize wearing compliance, accelerometers are positioned on the dorsal side of the participants' preferred wrist and attached with a locking wrist strap. Extensive description of the Actical monitor data screening and processing can be found elsewhere [66]. Briefly, after each monitoring period, accelerometers are removed by study staff and the data are downloaded to a computer using proprietary software (Actical Version 2.12). Each participant's data are then visually screened for adequate quality and quantity, to ensure wearing compliance, and that there is no evidence of monitor malfunctions. Given a 15 -second recording epoch, the monitors can collect a total of 11 successive days of data before memory saturation for all study participants. Raw data files are converted into minute-by-minute values of activity energy expenditure (AEE; $\mathrm{kcal} / \mathrm{kg} / \mathrm{min}$ ) using a previously published calibration algorithm [67]. Data are scanned to select consecutive 10-minute bouts of moderate- ( $\geq 0.0385$ $0.0895 \mathrm{kcal} / \mathrm{kg} / \mathrm{min}$ ) and vigorous-intensity (> $0.0895 \mathrm{kcal} / \mathrm{kg} / \mathrm{min})$ physical activity. Cutpoints were established previously in a sample similar to those in this study [66]. Although a potentially stronger measure of physical activity than pedometers, accelerometers were selected as a secondary measure of physical activity because at the time of grant funding and the beginning of the study, we had not yet clearly established appropriate cut points with which to estimate energy expenditure among African American women. We felt it was more appropriate to power the study on an instrument with established cut points for African American women. However, given the strength of the accelerometer as a measure, we also 
wanted to include it to provide an additional objective assessment of physical activity that, now that appropriate cut points have been established, should provide useful data on physical activity participation levels.

\section{Theoretical Framework Constructs}

As mentioned previously, L.A.D.I.E.S. was informed by social ecological theory and social cognitive theory. The concepts of self-efficacy, incentives, and social support were specific targets for the L.A.D.I.E.S. intervention, as our expectation was that directly targeting these behaviors would increase the likelihood of change in physical activity. Self-efficacy was assessed using a 16-item scale [68]. The first nine items measured participant's confidence in their ability to engage in physical activity while facing a variety of barriers (e.g., when tired, on vacation, during bad weather, during a personal crisis, etc).

Participants rated their confidence using a likert scale ranging from 0 ("Not at all confident") to 10 ("Completely confident"). The last six items assessed performance efficacy associated with physical activity as level of confidence for walking at a fast pace without stopping for (a) 10 minutes, (b) 20 minutes, (c) 30 minutes, (d) 40 minutes, and (e) 50 minutes. Each of these five periods of time was rated on a scale from 0 to 10 . The value 0 was anchored by the phrase "I cannot do at all", the value 5 by the phrase "Moderately certain I can do", and the value 10 by the phrase "Certain that I can do". The measure identifies two distinct subscales-desire for basic and advanced physical competencies. Both scales have high test-retest reliability $(>0.90)$, high internal consistency reliabilities $(>0.90)$, and modest correlation with the SF-36 $(r=0.23-0.42, \mathrm{p}<0.01)$.

The modified Social Provisions Scale (SPS) was used to assess social relations/support in the physical activity groups. The SPS is composed of 24 items with 4 items each reflecting six social provisions: social integration, reassurance of worth, reliable alliance, opportunity for nurturance, attachment, and guidance. The scores can also be combined for a total summary score [69]. Respondents were asked to think about their physical activity group and indicate their level of agreement $(1=$ strongly disagree, $2=$ disagree, $3=$ agree, $4=$ strongly agree) with a number of statements (e.g., "I feel uncomfortable in the physical activity group situations." "There are people in the physical activity group who believe in my abilities.") The internal consistency of the scale is excellent with Cronbach alphas exceeding .80 . Social provisions resulting from physical activity groups are related to longterm improvements in global quality of life and loneliness [69]. Additionally, a recent study found that the SPS was related to self-efficacy for physical activity, which was in turn related to actual physical activity levels [70].

Incentives were assessed as desire for physical activity and incentive for physical activity. In the desire for physical activity measure, participants were asked to indicate their level of desire to perform moderate-intensity physical activity for incremental time periods $(10,20$, $30,40,50$, and 60 minutes) on a scale ranging from 0 (no desire whatsoever) to 4 (very strong desire). This instrument is a modification of the scale used in previous studies [71, 72], and has been found to be valid and reliable (Cronbach alpha coefficients exceeding .80), related to self-efficacy, and to be responsive to physical activity interventions. Incentives for physical activity was assessed using a list of common reasons for participation in physical activity, each of which were rated on a 100\% likelihood scale and 9-point Likert scale reflecting the value of the item [73]. Likelihood and value were then multiplied to provide an incentive score. Items were grouped into two subscales: primary (outcomes one might expect as a direct result of participating in physical activity) and secondary incentives (those one might expect as a result of achieving the primary outcomes). Incentives could distinguish between adherers and non-adherers to physical activity in a community sample of 121 women ( $\mathrm{m}$ age 38.3 years) [73]. 


\section{Participant Characteristics}

During screening, data on participant age (self-reported and confirmed with date of birth) and self-reported race/ethnicity were collected to assure that all participants meet eligibility criteria. At baseline, data were collected on education, income, marital status, parental status and age of dependent children, household size, and employment status and hours worked/ week for descriptive purposes.

\section{Health-Related Quality of Life}

HRQL was measured using the 36 item short form of the Medical Outcomes Study questionnaire (SF-36) [74]. The SF-36 includes scales to measure the following dimensions: physical functioning, role limitations due to physical health problems, bodily pain, social functioning, general mental health, role limitations due to emotional problems, vitality, energy or fatigue and general health perceptions. The SF-36 has been widely used in health care research and can be self-administered or used in personal and telephone interviews. It has established reliability, validity and reference standards (norms for the general U.S. population for seven age groups and by gender) [75]. The SF-36 has also been shown to be valid and reliable when used with Black and white, as well as financial disadvantaged older adults, with chronic diseases, and obese individuals [76-80].

\section{Faith/Spirituality}

Questions on religion/spirituality were selected from a larger collection of surveys that have been identified as measures of religiousness/spirituality for use in health research [81-85]. These measures allowed us to identify the level of faith/spirituality present among individuals recruited in a faith-based setting and to determine whether varying levels of faith/spirituality impacted acceptability of the intervention and study outcomes. Questions included items on emotional support received from and provided to others within the participants' congregation, negative interactions with other congregation members, anticipate support from congregation members, religious/spiritual history, organizational religiousness, private religious practices, and an overall self-ranking of religiosity.

\section{Church-level data}

In addition to individual-level characteristics, we assessed factors that described the church setting, including size of church membership, number of active church members, number of weekly church services, ongoing health-related activities in each church, previous healthrelated activities or programs in the church, participation in other research studies at the church level, and participation in activities with other churches (to determine interaction with churches possibly involved in the proposed intervention but in another treatment assignment). These data were reported by the church liaison at baseline and then monthly via a mailed questionnaire. We tied payment of the monthly liaison stipend to receipt of the questionnaire to ensure timely data collection.

\section{Power and Statistical Analysis}

\section{Sample and Power}

The primary aim for L.A.D.I.E.S. is to test whether the faith-based or non-faith-based interventions are more effective than the control condition for increasing physical activity in underactive African American women. The primary outcome of the study was change in steps/day measured by pedometer. Data from the pilot study showed that average increases in daily steps were 1,013 at week 12 and 1,521 at week 24 with standard deviations of 1,584 and 2,524, respectively [86]. Assuming no change in steps/day for the control group, we based our sample size estimates on achieving an effect size of 0.6 (or approximately 1,500 
steps/day increase in the faith-based or non-faith-based intervention group compared to the control group). Furthermore, this study employed a cluster randomized design with randomization at church level and analysis at individual participant level; thus changes in steps of the participants from the same church were expected to be more similar compared to the participants from other churches (the intraclass correlation coefficient, ICC). Based on the pilot data, we estimated the ICC to be 0.0001 at month 10 and 0.026 at month 22 .

Because of the two planned primary comparisons of either the faith-based or non-faith-based intervention group with the control group, we further adjusted the significance level of each comparison to $\mathrm{p}=0.025$ in order to keep the overall type I error rate at $\mathrm{p}=0.05$. Although, we expect change to be in favor of intervention groups, we conservatively plan to use two-sided $\mathrm{t}$-tests after an omnibus $\mathrm{F}$ test to test if any two groups differ significantly at 0.05 probability level. Thus, estimated sample sizes provide $80 \%$ and $90 \%$ power to detect effect size of 0.6 at $\mathrm{p}=0.025$ for various number of churches in each study group, various cluster sizes (number of participants within a church), and ICC values ranging from 0.001 to 0.06 . After evaluating various sample size estimates, we decided to enroll 10 churches per condition and, on average, 15 participants within each church to provide at least $80 \%$ power to detect an effect size of 0.6 even for the ICC of 0.06 . We are interested in comparing two intervention groups as a secondary aim in an exploratory fashion. However, we do not expect to see a large difference in mean changes in steps/day between faith-based and nonfaith-based interventions and our sample size does not provide adequate power to detect any difference less than 1,500 steps/day between these two groups.

\section{Statistical Analysis}

The study's primary aim is to compare the efficacy of two active interventions (faith-based or non-faith-based) to a control condition for increasing daily physical activity measured as steps/day, at the conclusion of 10 months of active intervention. We will use a Generalized Linear Mixed Model (GLLM) which will include a random effect for churches and fixed effects for the baseline value of the steps/day and study groups to test if the change in steps/ day differed between any two groups using an overall $\mathrm{F}$ test under the intent to treat (ITT) principle and will include data on all participants. If this test is significant, we will proceed with two separate analyses: 1) comparing the mean changes in steps/day between faithbased curriculum and the control; 2) comparing the mean changes in steps/day between the non-faith-based curriculum and the control. To keep overall type I error rate at $\mathrm{p}=0.05$, each of the two comparisons will be performed at a significance level of $\mathrm{p}=0.025$. To further explore the effect of the intervention, we will fit multivariable GLMM models that (1) adjust for baseline covariates of interest, considered a priori, relevant to change in each outcome and examine the subgroup of completers only. We will compare the 10 month to 22 month outcomes or examine changes over 3 time points to determine if the effect is maintained, enhanced, or attenuated over time.

While we will make every effort to minimize attrition, drop out is expected due to length of follow-up. Therefore, we will compare respondents and non-respondents to see if they differ systematically on values of non-missing variables. The primary outcome analysis will be conducted under ITT principle using various imputations approaches. Imputation methods included will be 1) last observation carried forward, 2) missing follow-up steps/day imputed with zero change from baseline but with the same sample variance of those completed the study, 3) multiple imputations using PROC MI and will be combined using SAS software's PROC MI ANALYZE (Version 9.2, SAS Institute, Cary, NC). The results from these analyses will be compared to the result from analyses of those who completed the study (non-missing follow-up weight data). Furthermore, we will fit a selection model that allows the steps/day (primary outcome) data at follow-up to be missing not at random. In addition, we will also conduct a series of sensitivity analyses assuming various missing data patterns: 
those dropped out from the intervention groups will be assumed to reduce steps/day compared to no change in control group and have the same standard deviation of steps/day of those remained in the study. However, often times, it is hard to determine if "missingness" is ignorable and thus we further consider selection models (i.e., MNAR models) that allow data to be missing not at random to assess the effect of our intervention. We will also consider using various models to assess sensitivity of our results to various assumptions of missing data patterns. SAS software (Version 9.2, SAS Institute, Cary, NC) will be used for all analyses.

\section{Discussion/Conclusion}

Promoting physical activity within churches may be a viable intervention strategy, but the findings from previous studies are mixed. Conclusions from a recent review of faith-based physical activity interventions suggested that the current literature indicates that faith-based physical activity interventions are promising, but that improvements in study design, measurement, and theoretical framework are needed [22]. In addition, we believe additional work is needed to determine the impact of true faith-based interventions that fully incorporate faith tenets into the intervention content and that are compared, through rigorous study designs and evaluation, with alternate strategies, including minimal intervention conditions. L.A.D.I.E.S. capitalizes on elements of previous studies that have been shown to be successful and improves upon elements of previous studies that have been shown to be unsuccessful. L.A.D.I.E.S. included members of the clergy and the local faith-based community in the development of content for the faith-based curriculum, which was delivered from a faith perspective and incorporated scriptures and biblical messages within the program content. We utilized a Community Health Worker model such that individuals from the community served as intervention leaders and were partnered with a church liaison to assist with delivery of intervention content. The intervention content was culturally sensitive and included attention to surface and deep structure (e.g., content was delivered in churches by individuals who were familiar with the workings of the African American church; the faith-based curriculum was designed based on the notion that religious beliefs influence behavior and self-care). L.A.D.I.E.S. content incorporated scripture and prayer in both the faith- and non-faith-based curricula to control for churches that might add those elements in naturally as a part of church practice, and provided a faith-based curriculum that was strongly rooted in biblical principles and faith tenets, but could not be automatically delivered without training so that the faith- and non-faith-based curricula remained distinct. L.A.D.I.E.S. also focused on the positive benefits of physical activity on health, emphasized social support as one of the main mechanisms for behavior change, incorporated the church environment into strategies for changing physical activity-related behavior (e.g., offered exercise classes at the church), and trained church members on how to deliver the program after grant funding ended to increase the likelihood of program sustainability.

There are some potential limitations to the study that should be noted. L.A.D.I.E.S. is being evaluated in a sample of churches from urban and suburban communities in the Southeastern region of the United States. It is possible that churches included in the study and women who volunteered for a physical activity program are different from churches and women that declined participation in the study, or from churches and women in other regions of the United States. The L.A.D.I.E.S. curriculum included tenets from the historically black church tradition, and the curriculum may not be generalizable to white congregations or other denominations. L.A.D.I.E.S. used pedometers for data collection and self-monitoring. This was a potential limitation for the 10-month and 22-month data collection visits. Although the data collection monitor was sealed, participants in the active intervention conditions still had access to the pedometers used for self-monitoring, which were not sealed. If participants chose to wear both monitors during data collection, it is possible that 
having access to the pedometer data could have altered participant physical activity behaviors. We collected PA data for 14 days at each data collection visit. In our experience, participants may attempt to significantly alter PA behavior and may be successful for the first 1 - 3 days of data collection; however, after 3 days, participants are generally unable to maintain abnormal increases in PA. When we analyzed the PA data, we did not count the first three days of data collected. Our measures of faith/spirituality assess beliefs about associations between faith and general health and we acknowledge that our measures of faith/spirituality may not allow us to fully understand linkages between faith/spirituality and the specific behavior of physical activity. Finally, we are not powered to test small differences between the two active intervention arms.

L.A.D.I.E.S. is significant because it addresses a segment of the population most in need of interventions focused on increasing physical activity and delivered the program in a culturally relevant setting that incorporated important faith-based tenets. African American women have the highest levels of poor health outcomes associated with low levels of physical activity. Churches have a unique and important role in health promotion among African Americans, particularly women, and have been used to successfully impact a variety of health-related behaviors. Few effective interventions have been identified focused specifically on physical activity among African American women. Studies that have focused on delivering health promotion interventions in churches have had limited success which may be, in part, related to insufficient attention to the incorporation of faith tenets into intervention messages and materials, thus limiting program effectiveness and efficacy. L.A.D.I.E.S. will add to existing literature by describing an approach that is successful for initiating and sustaining change in a behavior that is a risk factor for various health outcomes associated with low levels of physical activity.

\section{Acknowledgments}

The authors acknowledge the support of our Community Advisory Board for their input in the development of intervention content: Mrs. Carol Henry, Reverend William Kearney, Mrs. Sharon Spease, Mrs. Hatti Taylor, and Mr. Lester Whitt. The authors thank Dr. Marino Bruce for comments on earlier drafts of this manuscript. The authors thank the African American Collaborative Obesity Research Network (AACORN) for their support.

Funding Source: The project described is supported by Award Number R01HL094580 from the National Heart, Lung, And Blood Institute. The content is solely the responsibility of the authors and does not necessarily represent the official views of the National Heart, Lung, And Blood Institute or the National Institutes of Health.

\section{References}

1. U.S. Department of Health and Human Services. Physical Activity and Health: A Report of the Surgeon General. U. S. Department of Health and Human Services, Centers for Disease Control and Prevention, National Center for Chronic Disease Prevention and Health Promotion; Hyattsville, MD: 1996.

2. Mayer-Davis EJ, et al. Intensity and amount of physical activity in relation to insulin sensitivity: the Insulin Resistance Atherosclerosis Study. JAMA. 1998; 279(9):669-74. [PubMed: 9496984]

3. Hu FB, et al. Television watching and other sedentary behaviors in relation to risk of obesity and type 2 diabetes mellitus in women. Jama. 2003; 289(14):1785-91. [PubMed: 12684356]

4. Bertoni AG, et al. The association between physical activity and subclinical atherosclerosis: the Multi-Ethnic Study of Atherosclerosis. Am J Epidemiol. 2009; 169(4):444-54. [PubMed: 19075250]

5. Kimm SY, et al. Decline in physical activity in Black girls and white girls during adolescence. The New England Journal of Medicine. 2002; 347(10):709-715. [PubMed: 12213941]

6. Troiano RP, et al. Physical activity in the United States measured by accelerometer. Med Sci Sports Exerc. 2008; 40(1):181-8. [PubMed: 18091006] 
7. Centers for Disease Control and Prevention. Prevalence of regular physical activity among adults-United States, 2001 and 2005. MMWR Morb Mortal Wkly Rep. 2007; 56(46):1209-12. [PubMed: 18030281]

8. Whitt-Glover MC, et al. Self-reported physical activity among blacks: estimates from national surveys. Am J Prev Med. 2007; 33(5):412-7. [PubMed: 17950407]

9. Whitt MC, et al. Walking patterns in a sample of African American, Native American, and Caucasian women: the cross-cultural activity participation study. Health Educ Behav. 2004; 31 (4 Suppl):45S-56S. [PubMed: 15296691]

10. Whitt M, Kumanyika S, Bellamy S. Amount and Bouts of Physical Activity in a Sample of African-American Women. Med Sci Sports Exerc. 2003; 35(11):1887-1893. [PubMed: 14600555]

11. Adams-Campbell LL, et al. Descriptive epidemiology of physical activity in African-American women. Prev Med. 2000; 30(1):43-50. [PubMed: 10642459]

12. National Center for Health Statistics. Health, United States, 2010: With special feature on death and dying. Hyattsville, MD: 2011.

13. Kennedy BM, et al. A pilot church-based weight loss program for African-American adults using church members as health educators: a comparison of individual and group intervention. Ethn Dis. 2005; 15(3):373-8. [PubMed: 16108295]

14. Fitzgibbon ML, et al. Results of a faith-based weight loss intervention for black women. J Natl Med Assoc. 2005; 97(10):1393-402. [PubMed: 16355489]

15. Kim KH, et al. The WORD (Wholeness, Oneness, Righteousness, Deliverance): A Faith-Based Weight-Loss Program Utilizing a Community-Based Participatory Research Approach. Health Educ Behav. 2006

16. Voorhees CC, et al. Heart, body, and soul: impact of church-based smoking cessation interventions on readiness to quit. Prev Med. 1996; 25(3):277-85. [PubMed: 8781005]

17. Oexmann MJ, et al. Short-term impact of a church-based approach to lifestyle change on cardiovascular risk in African Americans. Ethn Dis. 2000; 10(1):17-23. [PubMed: 10764126]

18. Wiist WH, Flack JM. A church-based cholesterol education program. Public Health Rep. 1990; 105(4):381-8. [PubMed: 2116640]

19. Smith ED, Merritt SL, Patel MK. Church-based education: an outreach program for African Americans with hypertension. Ethn Health. 1997; 2(3):243-53. [PubMed: 9426988]

20. Campbell MK, et al. The North Carolina Black Churches United for Better Health Project: intervention and process evaluation. Health Educ Behav. 2000; 27(2):241-53. [PubMed: 10768805]

21. Resnicow K, et al. Body and soul. A dietary intervention conducted through African-American churches. Am J Prev Med. 2004; 27(2):97-105. [PubMed: 15261895]

22. Bopp M, Peterson JA, Webb BL. A comprehensive review of faith-based physical activity interventions. American Journal of Lifestyle Medicine. In press.

23. Underwood SM, Powell RL. Religion and spirituality: influence on health/risk behavior and cancer screening behavior of African Americans. Abnf J. 2006; 17(1):20-31. [PubMed: 16596897]

24. Drayton-Brooks S, White N. Health promoting behaviors among African American women with faith-based support. Abnf J. 2004; 15(5):84-90. [PubMed: 15532240]

25. Chester DN, Himburg SP, Weatherspoon LJ. Spirituality of African-American women: correlations to health-promoting behaviors. J Natl Black Nurses Assoc. 2006; 17(1):1-8. [PubMed: 17004420]

26. Sbrocco T, et al. Church-based obesity treatment for African-American women improves adherence. Ethn Dis. 2005; 15(2):246-55. [PubMed: 15825971]

27. Bopp M, et al. Understanding physical activity participation in members of an African American church: a qualitative study. Health Educ Res. 2007; 22(6):815-26. [PubMed: 17138614]

28. Kumanyika SK, Charleston JB. Lose weight and win: a church-based weight loss program for blood pressure control among black women. Patient Educ Couns. 1992; 19(1):19-32. [PubMed: 1298945]

29. Lasater TM, et al. Synthesis of findings and issues from religious-based cardiovascular disease prevention trials. Annals of Epidemiology. 1997; S7:S46-S53. 
30. Lasater TM, et al. The role of churches in disease prevention research studies. Public Health Rep. 1986; 101(2):125-31. [PubMed: 3083467]

31. Olson LM, et al. The religious community as a partner in health care. J Community Health. 1988; 13(4):249-57. [PubMed: 3235715]

32. Goldmon MV, Roberson JT Jr. Churches, academic institutions, and public health: partnerships to eliminate health disparities. N C Med J. 2004; 65(6):368-72. [PubMed: 15714728]

33. The Barna Group. Church Attendance. 2007. [cited 2008 January 3]; Available from: http:// www.barna.org/FlexPage.aspx?Page=Topic $\&$ TopicID $=10$

34. The Pew Forum on Religion \& Public Life. US religious landscape survey Religious beliefs and practices: Diverse and politically relevant. Washington, DC: 2008.

35. Kosmin, BA.; Mayer, E.; Keysar, A. American Religious Identification Survey. 2001.

36. Campbell MK, et al. Church-based health promotion interventions: evidence and lessons learned. Annu Rev Public Health. 2007; 28:213-34. [PubMed: 17155879]

37. Resnicow K, et al. Cultural sensitivity in public health: defined and demystified. Ethn Dis. 1999; 9(1):10-21. [PubMed: 10355471]

38. Ard JD, Carter-Edwards L, Svetkey LP. A new model for developing and executing culturally appropriate behavior modification clinical trials for African Americans. Ethn Dis. 2003; 13(2): 279-85. [PubMed: 12785426]

39. Peterson J, Atwood JR, Yates B. Key elements for church-based health promotion programs: outcomebased literature review. Public Health Nurs. 2002; 19(6):401-11. [PubMed: 12406175]

40. Yanek LR, et al. Project Joy: faith based cardiovascular health promotion for African American women. Public Health Rep. 2001; 116(Suppl 1):68-81. [PubMed: 11889276]

41. Stokols D. Translating social ecological theory into guidelines for community health promotion. Am J Health Promot. 1996; 10(4):282-98. [PubMed: 10159709]

42. Baranowski, T.; Perry, CL.; Parcel, GS. How individuals, environments, and health behavior interact: Social Cognitive Theory. In: Glanz, K.; Lewis, FM.; Rimer, BK., editors. Health behavior and health education: Theory, research, and practice. 2. San Francisco, CA: Jossey-Bass, Inc; 1997. p. 153-178.

43. Bandura, A. Self-efficacy: the exercise of control. New York: Freeman; 1997.

44. Whitt-Glover MC, et al. Pilot Study of a Faith-Based Physical Activity Program Among Sedentary Blacks. Preventing Chronic Disease. 2008:5.

45. Kohl HW 3rd, et al. A randomized trial of physical activity interventions: design and baseline data from project active. Med Sci Sports Exerc. 1998; 30(2):275-83. [PubMed: 9502357]

46. Andersen RE, et al. Effects of lifestyle activity vs structured aerobic exercise in obese women: a randomized trial. Jama. 1999; 281(4):335-40. [PubMed: 9929086]

47. McAuley E, Blissmer B. Self-efficacy determinants and consequences of physical activity. Exerc Sport Sci Rev. 2000; 28(2):85-8. [PubMed: 10902091]

48. Bandura, A. Social Foundations of Thought and Action: A Social Cognitive Theory. Englewood Cliffs: Prentice Hall; 1986.

49. National Institute on Aging, National Institutes of Health, and U.S. Department of Health and Human Services. Exercise \& Physical Activity: Your Everyday Guide from the National Institute on Aging. 2010.

50. Corbie-Smith G, Thomas SB, St George DM. Distrust, race, and research. Arch Intern Med. 2002; 162(21):2458-63. [PubMed: 12437405]

51. Perri MG, Sears SF Jr, Clark JE. Strategies for improving maintenance of weight loss. Toward a continuous care model of obesity management. Diabetes Care. 1993; 16(1):200-9. [PubMed: 8422776]

52. Iwane M, et al. Walking 10,000 steps/day or more reduces blood pressure and sympathetic nerve activity in mild essential hypertension. Hypertens Res. 2000; 23(6):573-80. [PubMed: 11131268]

53. Lindberg R. Active living: on the road with the 10,000 Steps program. J Am Diet Assoc. 2000; 100(8):878-9. [PubMed: 10955038]

54. Wilde BE, Sidman CL, Corbin CB. A 10,000-step count as a physical activity target for sedentary women. Res Q Exerc Sport. 2001; 72(4):411-4. [PubMed: 11770790] 
55. Swartz AM, et al. Increasing daily walking improves glucose tolerance in overweight women. Prev Med. 2003; 37(4):356-62. [PubMed: 14507493]

56. Wyatt HR, et al. A Colorado statewide survey of walking and its relation to excessive weight. Med Sci Sports Exerc. 2005; 37(5):724-30. [PubMed: 15870624]

57. U. S. Department of Health and Human Services. 2008 physical activity guidelines for Americans. 2008.

58. Pate RR, et al. Physical activity and public health. A recommendation from the Centers for Disease Control and Prevention and the American College of Sports Medicine. JAMA. 1995; 273(5):4027. [PubMed: 7823386]

59. Horner S, Rew L, Torres R. Enhancing intervention fidelity: a means of strengthening study impact. J Spec Pediatr Nurs. 2006; 11(2):80-9. [PubMed: 16635187]

60. Craig CL, et al. International physical activity questionnaire: 12 -country reliability and validity. Med Sci Sports Exerc. 2003; 35(8):1381-95. [PubMed: 12900694]

61. Whitt-Glover MC, et al. A calibration method to improve criterion validity of self-reported physical activity. Journal of Physical Activity and Health. Under review.

62. Cardinal BJ. Assessing the physical activity readiness of inactive older adults. Adapted physical activity quarterly. 1997; 14:65-73.

63. Cardinal BJ, Cardinal MK. Screening efficiency of the revised physical activity readiness questionnaire in older adults. Journal of Aging and Physical Activity. 1995; 3:299-308.

64. Cardinal BJ, Cardinal MK. Preparticipation physical activity screening within a racially diverse, older adult sample: comparison of the original and Revised Physical Activity Readiness Questionnaires. Res Q Exerc Sport. 2000; 71(3):302-7. [PubMed: 10999267]

65. Cardinal BJ, Esters J, Cardinal MK. Evaluation of the revised physical activity readiness questionnaire in older adults. Med Sci Sports Exerc. 1996; 28(4):468-72. [PubMed: 8778552]

66. Heil DP, et al. Influence of moderate intensity cut point on free living physical activity outcome variables. Med Sci Sports Exerc. 2007; 39(5):S185.

67. Heil DP. Predicting energy expenditure using the Actical activity monitor. Res Q Exerc Sport. 2006; 77(1):64-80. [PubMed: 16646354]

68. Katula JA, Rejeski WJ, White L. Desire for physical competence: understanding motives for physical activity in older adults. Med Sci Sports Exerc. 2006; 36(5):S282-S283.

69. McAuley E, et al. Social relations, physical activity, and well-being in older adults. Prev Med. 2000; 31(5):608-17. [PubMed: 11071843]

70. Motl RW, et al. Correlates of physical activity among individuals with multiple sclerosis. Annals of behavioral medicine: a publication of the Society of Behavioral Medicine. 2006; 32:154-161. [PubMed: 16972813]

71. Katula JA, et al. Strength training in older adults: an empowering intervention. Med Sci Sports Exerc. 2006; 38(1):106-11. [PubMed: 16394961]

72. Rejeski WJ, et al. Older adults' desire for physical competence. Med Sci Sports Exerc. 2006; 38(1):100-5. [PubMed: 16394960]

73. Rodgers WM, Gauvin L. Heterogeneity of incentives for physical activity and self-efficacy in highly active and moderately active women exercisers. Journal of Applied Social Psychology. 1998; 28:1016-1029.

74. Ware, JE, Jr. Sf-36 Health Survey: Manual and Interpretation Guide. Boston: The Health Institute, New England Medical Center; 1993.

75. McDowell, I.; Newell, C. Measuring Health: A Guide to Rating Scales and Questionnaires. 2. New York: Oxford; 1996.

76. Fontaine KR, Cheskin LJ, Barofsky I. Health-related quality of life in obese persons seeking treatment. J Fam Pract. 1996; 43(3):265-70. [PubMed: 8797754]

77. Johnson PA, et al. Comparison of the Medical Outcomes Study Short-Form 36-Item Health Survey in black patients and white patients with acute chest pain. Med Care. 1995; 33(2):145-60.

[PubMed: 7837823] 
78. McHorney CA, et al. The MOS 36-item Short-Form Health Survey (SF-36): III. Tests of data quality, scaling assumptions, and reliability across diverse patient groups. Med Care. 1994; 32(1): 40-66. [PubMed: 8277801]

79. Wolinsky FD, Stump TE. A measurement model of the Medical Outcomes Study 36-Item ShortForm Health Survey in a clinical sample of disadvantaged, older, black, and white men and women. Med Care. 1996; 34(6):537-48. [PubMed: 8656720]

80. Wolinsky FD, Wan GJ, Tierney WM. Changes in the SF-36 in 12 months in a clinical sample of disadvantaged older adults. Med Care. 1998; 36(11):1589-98. [PubMed: 9821946]

81. Fetzer Institute and National Institute on Aging Working Group. Multidimensional measurement of religiousness/spirituality for use in health research: a report of the Fetzer Institute/National Institute on Aging Working Group. Kalamazoo, MI: Fetzer Institute; 2003.

82. Idler, E. Fetzer Institute and National Institute on Aging Working Group. Multidimensional measurement of religiousness/spirituality for use in health research: a report of the Fetzer Institute/ National Institute on Aging Working Group. Fetzer Institute; Kalamazoo, MI: 2003. Values.

83. Krause, N. Fetzer Institute and National Institute on Aging Working Group. Multidimensional measurement of religiousness/spirituality for use in health research: a report of the Fetzer Institute/ National Institute on Aging Working Group. Fetzer Institute; Kalamazoo, MI: 2003. Religious support.

84. George, LK. Fetzer Institute and National Institute on Aging Working Group. Multidimensional measurement of religiousness/spirituality for use in health research: a report of the Fetzer Institute/ National Institute on Aging Working Group. Fetzer Institute; Kalamazoo, MI: 2003. Religious/ spiritual histor.

85. Idler, E. Fetzer Institute and National Institute on Aging Working Group. Multidimensional measurement of religiousness/spirituality for use in health research: a report of the Fetzer Institute/ National Institute on Aging Working Group. Fetzer Institute; Kalamazoo, MI: 2003. Organizational religiousness.

86. Whitt-Glover MC, et al. Pilot study of a faith-based physical activity program among sedentary blacks. Prev Chronic Dis. 2008; 5(2):A51. [PubMed: 18341786] 
Table 1

Learning and Developing Individual Exercise Skills (L.A.D.I.E.S.) for a Better Life Session Content

\begin{tabular}{|c|c|c|}
\hline Session & Title & Goals \\
\hline 0 & Ready, Set, Go & $\begin{array}{l}\text { To introduce participants to the program and let them know what is expected for the } \\
\text { next } 10 \text { months }\end{array}$ \\
\hline 1 & Getting Started & $\begin{array}{l}\text { To get participants thinking about the importance of self-care and to discuss current and } \\
\text { previous physical activity experiences }\end{array}$ \\
\hline 2 & Monitoring Physical Activity & $\begin{array}{l}\text { To equip participants with the knowledge and materials to monitor their physical } \\
\text { activity. }\end{array}$ \\
\hline 3 & Safety & $\begin{array}{l}\text { To equip participants with the knowledge necessary to understand how to exercise } \\
\text { safely. }\end{array}$ \\
\hline 4 & Goal Setting & $\begin{array}{l}\text { To equip participants with the knowledge and skills necessary to set goals using the } \\
\text { SMART principles. }\end{array}$ \\
\hline 5 & Personality Traits and Physical Activity & $\begin{array}{l}\text { To equip participants with information about the relationship between personality traits } \\
\text { and physical activity. }\end{array}$ \\
\hline 6 & Review and Trouble Shooting & $\begin{array}{l}\text { To allow participants to discuss and problem solve about specific issues they might be } \\
\text { facing and to ask questions about content covered during previous sessions }\end{array}$ \\
\hline 7 & Benefits of Physical Activity & $\begin{array}{l}\text { To equip participants with knowledge of the benefits of physical activity and the } \\
\text { mechanisms by which physical activity impacts the body. }\end{array}$ \\
\hline 8 & $\begin{array}{l}\text { Adding Physical Activity to Your Daily } \\
\text { Routine }\end{array}$ & $\begin{array}{l}\text { To focus on creating active lifestyles by equipping participants with the skills to be able } \\
\text { to identify opportunities to add physical activity to the usual daily routine. }\end{array}$ \\
\hline 9 & Time Management & $\begin{array}{l}\text { To equip participants with the skills necessary to effectively manage daily duties to } \\
\text { allow time for physical activity. }\end{array}$ \\
\hline 10 & Getting the Support You Need & To understand the importance of social support \\
\hline 11 & Review and Trouble Shooting & $\begin{array}{l}\text { To allow participants to discuss and problem solve about specific issues they might be } \\
\text { facing and to ask questions about content covered during previous sessions }\end{array}$ \\
\hline 12 & $\begin{array}{l}\text { Barriers/Problem Solving: Women's } \\
\text { Issues }\end{array}$ & $\begin{array}{l}\text { To equip participants with the skills necessary to identify and negotiate barriers to } \\
\text { physical activity that might be specific for women. }\end{array}$ \\
\hline 13 & Gaining Confidence & $\begin{array}{l}\text { To continue to increase confidence in the ability to engage in regular moderate-intensity } \\
\text { physical activity. }\end{array}$ \\
\hline 14 & Rewarding Yourself & $\begin{array}{l}\text { To identify small (or large) ways participants can reward themselves to celebrate } \\
\text { reaching physical activity goals. }\end{array}$ \\
\hline 15 & Review and Trouble Shooting & $\begin{array}{l}\text { To allow participants to discuss and problem solve about specific issues they might be } \\
\text { facing and to ask questions about content covered during previous sessions }\end{array}$ \\
\hline 16 & Avoiding Pitfalls & $\begin{array}{l}\text { To understand potential pitfalls or people, places, and/or things in life that might derail } \\
\text { plans for physical activity. }\end{array}$ \\
\hline 17 & Strategies for Continued Success & $\begin{array}{l}\text { To identify strategies that will enable participants to continue to be successful with } \\
\text { increasing and maintaining increased levels of physical activity, even though weekly } \\
\text { sessions are ending. }\end{array}$ \\
\hline 18 & Importance of Rest and Sleep & $\begin{array}{l}\text { To understand the importance of rest and sleep, in addition to physical activity, for } \\
\text { health benefits. }\end{array}$ \\
\hline 19 & Stress Reduction & $\begin{array}{l}\text { To understand the signs of stress, the negative effects of stress, and to identify methods } \\
\text { to help reduce and/or deal with stress in our daily lives. }\end{array}$ \\
\hline 20 & Review and Trouble Shooting & $\begin{array}{l}\text { To allow participants to discuss and problem solve about specific issues they might be } \\
\text { facing and to ask questions about content covered during previous sessions }\end{array}$ \\
\hline 21 & $\begin{array}{l}\text { Self and Body Awareness } \\
\text { (Mindfulness) }\end{array}$ & $\begin{array}{l}\text { To highlight the importance of self and body awareness and the importance of paying } \\
\text { attention to one's body, thoughts, and feelings throughout the day. This session will also } \\
\text { introduce the concepts of deep stretching and yoga. }\end{array}$ \\
\hline 22 & Exploring New Activities & $\begin{array}{l}\text { To highlight the importance of trying new activities and to identify physical activity } \\
\text { options in your home/community. }\end{array}$ \\
\hline
\end{tabular}




\begin{tabular}{|l|l|l|}
\hline Session & Title & Goals \\
\hline 23 & $\begin{array}{l}\text { Relapse Prevention- Maintaining } \\
\text { Behavior }\end{array}$ & To understand how to handle lapses and relapses in your physical activity program. \\
\hline 24 & Next Steps & $\begin{array}{l}\text { To determine their current stage of readiness for physical activity, rate the skills and } \\
\text { strategies that work best for them, and make a commitment for physical activity during } \\
\text { the coming year. }\end{array}$ \\
\hline
\end{tabular}

